\title{
Methods for air tightness analysis for residential buildings in Nordic countries
}

\author{
I. Allard, T. Olofsson \& O. A. B. Hassan \\ Department of Applied Physics and Electronics, \\ Umeå University, Sweden
}

\begin{abstract}
Envelope air tightness is one factor that has impact on the energy performance of buildings. The goals of the directive 2010/31/EU, on energy performance of buildings, raise the importance of building energy performance analysis in the process. Measurements of air tightness can be useful both when evaluating building energy performance and developing new building techniques. The aim of this paper is to review and evaluate methods to measure air tightness in both new and existing residential buildings in Sweden, Norway and Finland, based on an international literature study and a survey. The methods are categorized based on a number of criteria to determine their suitability in different situations. Advantages and disadvantages of the methods are discussed, as well as commonly used methods in the three countries. The review shows that the standard ISO 9972 is used for verification in all three countries, but alternatives exist that might be more suitable in certain situations. Simpler methods are used in the building process to increase air tightness. To achieve a comparable measurement, both common methods and commonly defined units are needed. Keywords: air tightness measurements, residential buildings, cold climate, energy use, building regulations.
\end{abstract}

\section{Introduction}

Buildings have a significant impact on the environment, through resource and energy use. Sustainable buildings minimize environmental impact and promote energy efficiency, economic, and social benefits [1]. To meet the goals of the directive 2010/31/EU [2], the building sector in Europe faces a transition towards more energy efficient buildings. The importance is heightened in the 
Nordic countries, where the climate is cold most of the year. Air tightness affects energy efficiency through involuntary ventilation, insulating capacity of the envelope materials and efficiency of the ventilation heat exchanger. Air tightness also affects human health and productivity through indoor air quality, contaminants and thermal comfort; fire safety; acoustic insulation; and construction quality through moisture and mold problems. These factors are discussed in earlier reports on building air tightness [3,4]. Altogether, air tightness is an important factor for sustainable buildings. The transition towards energy efficient buildings will require testing and the importance of air tightness analysis will increase.

A number of reviews on building air tightness issues have been written, with different focus. Papers on air tightness standards and trends discuss the difficulties in comparing air tightness with different units of measure $[5,6]$. Common units are air changes per hour, $n_{\Delta p}$, air permeability, $q_{\Delta p}$, specific leakage rate, $w_{\Delta p}$, and effective leakage area, ELA. The review [3] covers techniques to measure air tightness of building envelopes in a number of countries. Normalizationsare also discussed and the use of different pressure differentials over the envelope. Building volume is used for $n_{\Delta p r}$, envelope area is used for $q_{\Delta p}$ (which makes it a kind of porosity measure) and floor area is used for $w_{\Delta p}$. Infiltration depends on the pressure differential across the envelope, but air tightness does not. Air tightness is measured with highest accuracy at high pressures, but this does not give a measure of the infiltration under natural conditions. $50 \mathrm{~Pa}$ is most commonly used for single point measurements, followed by $25 \mathrm{~Pa}$. $75 \mathrm{~Pa}$ is used for single components and $4 \mathrm{~Pa}$ to simulate weather induced pressure. The reviews [7] and [8] cover air tightness criteria and measurement techniques. The study [9] focuses on tracer gas methods and the survey [10] on the ISO 9972 air tightness standard in a number of European countries. The study [4] describes alternative methods to analyse air tightness.

The aim of this paper is to review and evaluate methods to analyse air tightness in residential buildings in Sweden, Norway and Finland. The goal is to map and categorize the methods, as a platform for further work. The review is based on a literature study of regulations, specifications and methods for air tightness analysis and a survey of the three participating countries.

\section{Review}

\subsection{Methods for air tightness analysis}

In this section, 13 methods for air tightness analysis, used in practice as well as found in literature in the three Nordic countries, are presented.

\subsubsection{Ocular inspection}

Ocular inspection is the most basic method used to evaluate air tightness in the building process. The building, or building parts, is visually inspected; cracks and clear leakage risk-areas are assessed. The inspection is often combined with 
an examination of the drawings and the quality is dependent on the knowledge and experience of the specialist performing it [4].

\subsubsection{Acoustic measurements}

The ISO 140 standard [11] describes methods to measure sound insulation in façade elements and complete facades. A signal with certain frequency content is generated to measure sound transmissions through openings, holes and cracks [12]. High sound transmission could suggest air leaks. A transmitter or noise source, a receiver in the form of a microphone and a frequency analyzerto display the impulse response [Hz] is needed. Based on wavelength, infrasound can be used to measure whole buildings, audible sound for building parts and ultrasound for single cracks. Ultrasounds works only for consistent cracks through the wall, or the sound is absorbed. For audible sound, a reference value is also required [4]. The results can be confirmed by comparing a theoretically calculated sound reduction index, $\mathrm{R}[\mathrm{dB}]$, to one calculated based on the measurements. The leakage area can then be calculated [12].

\subsubsection{Light measurements}

Light measurements are primarily used to inspect ducts, but can also be used to inspect building envelopes. Lamps emitting white or ultraviolet light are used and a visual inspection is made of where the light shines through the envelope. When using white light, the surrounding has to be dark. Only consistent cracks through the wall can be found using this method [4].

\subsubsection{Hand inspection}

When using the hand to inspect air tightness, the building is pressurized to a negative pressure to enhance draughts at points with high leakage. A colder outdoor than indoor temperature makes the draughts easier to detect. Hand inspection is often combined with air velocity-measurements [4].

\subsubsection{Surface temperature measurements/thermography}

Surface temperature measurements, with a surface temperature meter or IRcamera, can be used both on building parts, single zones and whole buildings. A supplementary measurement of air velocity can be performed when leakage points are identified. A temperature difference of 5 degrees over the envelope is required. The infrared radiation measured by an IR-camera is influenced by leakage, surface emissivity, insolation and thermal bridges [4]. The EN 13187 standard for thermography is used in Sweden and Norway [13]. In Finland, surface temperature is measured according to a surface temperature index defined in the SFS 5511 standard [14] and guidelines from the Ministry of Social Affairs and Health [15]. Two guidelines are used for thermography [16, 17].

\subsubsection{Air velocity measurements}

Air velocity measurements are included in the ISO 7726 [18] and 7730 [19] standards. The European EN 13182 standard [20] describes characteristics of air velocity measuring devices. In Finland, guidelines for air velocity measurements exist in an instruction card from the building information group (Rakennustieto 
[21]), and from the Finnish Standard Association (SFS [14]). Air velocity target values, in $\mathrm{m} / \mathrm{s}$, are specified by Rakennustieto [22]. The measurements are done under a negative pressure, when leakage risk areas are known. An anemometer, with $<3 \%$ error, is proposed for the measurements [4]. Small flows can be measured using Laser Doppler Velocimetry [8].

\subsubsection{Smoke}

There is no international ISO standard for smoke measurements; it is described in a standard from the American Society of Testing and Materials (ASTM) [23]. A smoke pen or a smoke bottle is usedunder pressurization, and a visual assessment is made. A positive pressure in the building pushes the smoke out through any cracks, while a negative pressure sucks the smoke in [4].

\subsubsection{Soap bubble method}

There is no international ISO standard for this method, but it is described in a standard from the American Society of Testing and Materials (ASTM) [23]. Measurements are performed under a negative pressurization. The soap bubble solution is applied to a surface and bubbles are formed where air is leaking out. Big leaks can be difficult to discover, when thebubbles crack quickly [4].

\subsubsection{Tracer gas method}

Tracer gas can be used to evaluate air tightness during normal pressure conditions. Whole buildings and single zones can be measured; multiple zones with use of multiple gases. The total air change rate is measured, with $5-10 \%$ expected error [8]. A tracer gas and an analyser, to measure the concentration, are used. Nitrous oxide, $\mathrm{N}_{2} \mathrm{O}$, is widely used in Europe [24]. The ASTM standard E741 [26] describes methods; gas decay, constant injection or constant concentration. Tracer gas decay is regulated in the ISO 12569 standard [26] and the Nordtest NT VVS 055 standard [27], used in Finland. The tracer gas is let in, mixed in the zone to a uniform concentration and then turned off. The average ventilation rate is determined by measuring initial and final gas concentration [8]. Measurements in multiple points can account for imperfect mixture of the tracer gas [24]. Constant injection is regulated in the Nordtest NT VVS 105 standard [28] in Finland. It is more appropriate than tracer gas decay for leaky spaces [8] and makes it possible to measure changes in the ventilation rate. The concentration is measured in one point, during a constant gas inlet, and used to calculate the ventilation rate. The settling time to reach concentration equilibrium can be long, resulting in large gas consumption [24]. Constant gas concentration is more appropriate for continuous measurements when the ventilation rate is unsteady. A feedback control loop is used to regulate the inlet of tracer gas and provide a stable concentration level. The equipment is complicated, but the uncertainty is normally $<5 \%$.Aninstantaneous tracer gas measurement can also be performed by injecting a pulse of tracer gas into the air supply, while measuring the concentration at a point some distance away [8]. 


\subsubsection{Fan pressurization}

The fan pressurization method is used to evaluate air tightness. A fan is mounted in an opening and the air flow thorough the fan required to achieve specific pressure differences is measured. Adoor mounted fan, "Blower door", is often used. The power-law formula is the most common model used to characterize air leakage, based on the relationship between air flow and pressure difference [3].

\subsubsection{According to standard ISO 9972/EN 13829 The ISO 9972/EN 13829} standard [29] presents a fan pressurization method, referenced to in the general ISO 13790 standard [31] on energy performance of buildings. Itdefines a procedure for a stationary fan pressurization test with a blower door. The method is designed for one-zone buildings. Buildings with multiple zones can be regarded as one by opening doors etc. Individual components are not addressed. For large or leaky buildings, the buildings ventilation system can be used instead of a blower door. The air flow and induced pressure difference is measured, in steps $\leq 10 \mathrm{~Pa}$. Pressures between 10 and $50 \mathrm{~Pa}$ are prescribed for small houses, but pressures up to $100 \mathrm{~Pa}$ are recommended. Two tests with at least five data points should be performed, one with positive pressure differentials and one with negative. The overall uncertainty will be $<15 \%$ in most cases.Changes in the building envelope, caused by the pressure, can increase the uncertainty. The measured data can be calculated to $n_{\Delta p}, q_{\Delta p}$ or $w_{\Delta p}$ [29]. Two variants of the method, A and B, are described in the standard. A is a test of the building in use and the envelope should represent normal conditions during the season when the heating or cooling system is in use. Method B is a test of the envelope, all adjustable openings should be closed and remaining intentional openings sealed. Method B is primarily used in Norway [10] and Finland. In Finland, air tightness testing is also regulated by a national standard [31]. Method A is used for small buildings and single residential buildings in Sweden, B for larger buildings.

2.1.10.2 Extrapolation of data points A50 $\mathrm{Pa}$ pressure differential can be difficult to achieve with standard fan equipment in large or leaky buildings. Extrapolation to $50 \mathrm{~Pa}$ from lower pressures is then recommended to make comparisons possible between buildings [4]. Extrapolation is also used to transform the air leakage at $50 \mathrm{~Pa}$ to a pressure range experienced by the building in natural conditions. Studies show that results from measurements from higher pressure ranges safely can be extrapolated to natural pressure [32]. The uncertainty using only 2 measurements is $13 \%$ [33].

2.1.10.3 Pressure testing of single zones or apartments In large buildings, single zones or apartments can be measured and taken to represent the whole building. Measurements can be done in three ways: calculated for total immersive area; calculated for the envelope surface toward the outside; or calculated on the envelope surface towards the outside with a balancing pressure created in nearby apartments. The third alternative, called balanced fan pressurization [7], is more accurate but requires more equipment. Air leakage can vary between apartments within the same building; larger apartments are often leakier since they have more walls towards the outside [3, 4]. Articles on 
this method are published by international organizations like ASHRAE. The uncertainty of the measurements is within $15 \%$ [34].

2.1.10.4 Individual building components Building components can be tested under pressurization, most accurately in a laboratory. Standardized procedures often exist for windows and doors, but laboratory measurements are less appropriate for wall or roof components. A chamber or extra wall can be used on site. Internal leakages can be eliminated if the room outside the chamber or wall is pressurized to a balancing pressure [4]. Whole building pressurization can be used to evaluate leakage path distribution, by selectively sealing different paths. This is known as reductive sealing. A pressure compensating flow rate meter, operating on a zero pressure principle, can be used for the reductive sealing, test chamber or extra wall. Internal leak flows will then be minimal [7].

2.1.10.5 Transient pressurization The transient method is a dynamic approach. When the volume is pressurized and air supply is turned off, the pressure decreases in a characteristic way for the degree of air leakage. The result is a continuous function between pressure and air leakage. A pressure pulse could be used to create the initial pressure. Taking temperature changes into account, the transient method agree well with the static pressurization method. Changes in the building envelope caused by the pressure can increase the uncertainty. Unknown volume changes can be determined by a second measurement with an additional, known, leakage flow. A test measurement of an attic floor shows an uncertainty $<15 \%$ at high pressures, but the technique requires more testing for whole buildings. Heat flow between air and solid materials created by the pressure change may also affect the leakage rate. Because of this, the transient method could be used to determine the overall surface heat transfer coefficient [35].

\subsubsection{Pressurization with building system}

The buildings ventilation system can be used for the pressurization, by turning of the return and exhaust air. The method is described in the Canadian standard, CAN/CGSB-149.15-96 [36]. A control system for the ventilation system is required to change the pressure with accuracy [4]. The air flow can be measured with tracer gas if meters cannot be installed in the ventilation system [8]. The method can be used for whole buildings or single zones serviced by their own air handlers. With single zones, all adjacent zones also need to be pressurized. Pressure differentials should be between 10 and $60 \mathrm{~Pa}$, with a series of 5-10 Pa intervals. Measurements of air volume flow, using air flow measuring probes, have been shown to have an uncertainty of $2,1-6,3 \%$ [37].

\subsubsection{AC pressurization}

With $\mathrm{AC}$ pressurization, a piston is used to create a fluctuating pressure, by inducing a small sinusoidal change of the internal volume. The pressure is measured and the phase relationship between this and the velocity of the piston is used to evaluate the air leakage. The method only works for laminar flow and large leaks can go undetected. This technique is currently not in use; it is complicated, but can be used when a fan is impossible to use. It also allows 
building air tightness to be analysed at low pressure differentials with a minimal interference from climatic forces [3, 7]. The resulting pressure from the volume change is around $4 \mathrm{~Pa}$ and the error for measuring air flow corresponding to a pressure difference of $5 \mathrm{~Pa}$ is estimated to $5 \%$ [38].

\subsubsection{Pulse pressurization}

Pulse pressurization is another dynamic air tightness measurement. A pressure pulse is introduced on the inside, with a pressurized air tank, and the pressure drop is measured. The method works only for laminar flow, which limits the use to small homes or apartments since unsteady flow can develop from pressure differences in the measured space [3]. The method is not very accurate, but installation of heavy equipment is avoided. The measured pressure decay is fitted to theoretical values to determine the leakage characteristics [7]. The initial pressure pulse could also be induced from closing a door or by an airbag [35].

\subsection{Comparison of methods for air tightness analysis}

Tables 1 and 2 present a summary of the studied methods. The methods are categorized based on a number of criteria to help determine their suitability in different situations: first according to standardization; as generally known methods, methods defined by national or international standards or experimental methods. The standardization affects how the method is used today and how good it would work as a common measurement of air tightness in the three Nordic countries. The methods are also categorized based on their aim to improve or to verify building air tightness and based on their application - in the building process (including refurbishments), for new, or for existing buildings. Measurements in the building process are often qualitative and used to improve air tightness, while new or existing buildings more often are analyzed quantitatively to verify air tightness. Another classification is based on what the methods are best suited to measure - building parts, single zones or apartments, whole buildings or large buildings. The measured quantity, unit, pressure differential, normalization used and uncertainty are also presented for each method, to enable comparisons. Finally, an assessment of the methods technological complexity is made, where low represents methods with simple methodology and simple or no necessary equipment and high represents methods with complex methodology and/or a lot of equipment required.

In the building process, there are several methods to analyze building air tightness - from simple methods, without either pressurization or complex equipment, to more advanced methods with both pressurization and measuring equipment of different kind. Simple methods (e.g. ocular inspection) are often enough to identify and fix the worst leaks at an early stage. Depending on the required accuracy level, two or more methods can be combined (e.g. smoke and air velocity measurements). Leaks are easy to fix when they are identified at an early stage, but become more difficult and expensive to fix later in the building process or in connection with a final, quantitative, air tightness test. 


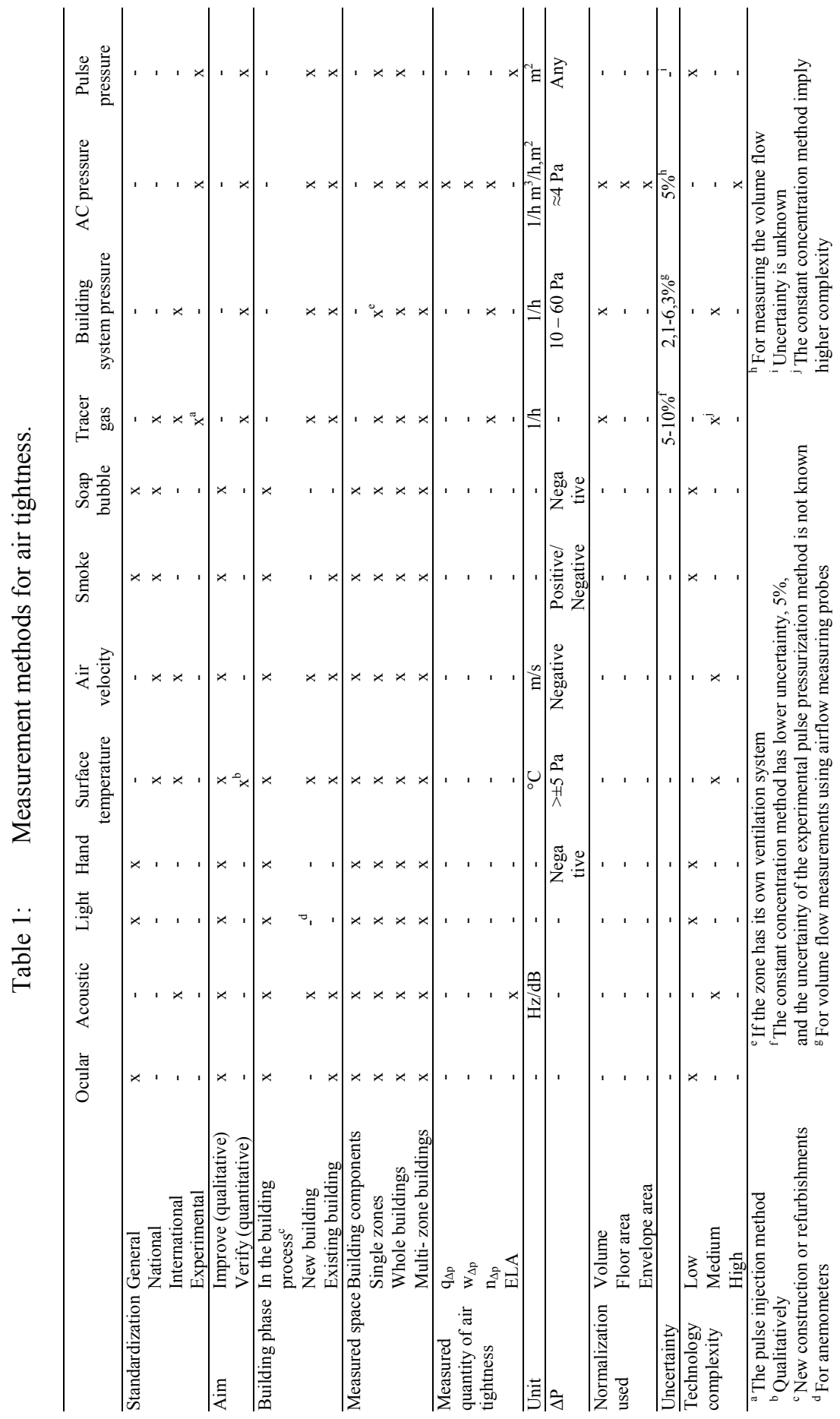


Table 2: $\quad$ Fan pressurization methods for air tightness.

\begin{tabular}{|c|c|c|c|c|c|c|}
\hline & & $\begin{array}{c}\text { Standard } \\
\text { EN } 13829\end{array}$ & $\begin{array}{l}\text { Extrapol } \\
\text { ation }\end{array}$ & $\begin{array}{l}\text { Single } \\
\text { zones }\end{array}$ & $\begin{array}{c}\text { Building } \\
\text { components }\end{array}$ & $\begin{array}{l}\text { Transient } \\
\text { method }\end{array}$ \\
\hline \multirow[t]{4}{*}{ Standardization } & General & - & $\mathrm{x}$ & $\mathrm{x}$ & - & - \\
\hline & National & - & - & - & $\mathrm{x}$ & - \\
\hline & International & $\mathrm{x}$ & - & - & - & - \\
\hline & Experimental & - & - & - & $\mathrm{x}$ & $\mathrm{x}$ \\
\hline \multirow[t]{2}{*}{ Aim } & Improve & - & - & - & $\mathrm{x}$ & - \\
\hline & Verify & $\mathrm{x}$ & $\mathrm{x}$ & $\mathrm{x}$ & - & $\mathrm{x}$ \\
\hline \multirow[t]{3}{*}{ Building phase } & $\begin{array}{l}\text { In the building } \\
\text { process }^{\mathrm{a}}\end{array}$ & - & - & - & $\mathrm{x}$ & - \\
\hline & New building & $\mathrm{x}$ & $\mathrm{x}$ & $\mathrm{x}$ & - & $\mathrm{x}$ \\
\hline & Existing building & $\mathrm{x}$ & $\mathrm{x}$ & $\mathrm{x}$ & - & $\mathrm{x}$ \\
\hline \multirow[t]{4}{*}{$\begin{array}{l}\text { Measured } \\
\text { space }\end{array}$} & $\begin{array}{l}\text { Building } \\
\text { components }\end{array}$ & - & - & - & $\mathrm{x}$ & $\mathrm{x}$ \\
\hline & Single zones & $\mathrm{x}$ & - & $\mathrm{x}$ & - & $\mathrm{x}$ \\
\hline & Whole buildings & $\mathrm{x}$ & $\mathrm{x}$ & - & - & - \\
\hline & $\begin{array}{l}\text { Multi-zone } \\
\text { buildings }\end{array}$ & - & $\mathrm{x}$ & - & - & - \\
\hline \multirow{4}{*}{$\begin{array}{l}\text { Measured } \\
\text { quantity of air } \\
\text { tightness }\end{array}$} & $\mathrm{q}_{\Delta \mathrm{p}}$ & $\mathrm{x}$ & $\mathrm{x}$ & $\mathrm{x}$ & $\mathrm{x}$ & $\mathrm{x}$ \\
\hline & $\mathrm{w}_{\Delta \mathrm{p}}$ & $\mathrm{x}$ & $\mathrm{x}$ & - & $\mathrm{x}$ & $\mathrm{x}$ \\
\hline & $\mathrm{n}_{\Delta \mathrm{p}}$ & $\mathrm{x}$ & $\mathrm{x}$ & - & $\mathrm{x}$ & $\mathrm{x}$ \\
\hline & ELA & - & - & - & - & - \\
\hline Unit & & $\begin{array}{c}1 / \mathrm{h} \\
\mathrm{m}^{3} / \mathrm{h}, \mathrm{m}^{2}\end{array}$ & $\begin{array}{c}1 / \mathrm{h} \\
\mathrm{m}^{3} / \mathrm{h}, \mathrm{m}^{2}\end{array}$ & $\mathrm{~m}^{3} / \mathrm{h}, \mathrm{m}^{2}$ & $\begin{array}{c}1 / \mathrm{h} \\
\mathrm{m}^{3} / \mathrm{h}, \mathrm{m}^{2}\end{array}$ & $\begin{array}{c}1 / \mathrm{h} \\
\mathrm{m}^{3} / \mathrm{h}, \mathrm{m}^{2}\end{array}$ \\
\hline $\begin{array}{l}\text { Pressure } \\
\text { difference }\end{array}$ & & $50 \mathrm{~Pa}$ & $25 \mathrm{~Pa}$ & $50 \mathrm{~Pa}$ & $0-200 \mathrm{~Pa}$ & $>100 \mathrm{~Pa}$ \\
\hline \multirow{3}{*}{$\begin{array}{l}\text { Normalization } \\
\text { used }\end{array}$} & Volume & $\mathrm{X}$ & $\mathrm{x}$ & - & $\mathrm{X}$ & $\mathrm{x}$ \\
\hline & Floor area & $\mathrm{x}$ & $\mathrm{x}$ & - & $\mathrm{x}$ & $\mathrm{x}$ \\
\hline & Envelope area & $\mathrm{x}$ & $\mathrm{x}$ & $\mathrm{x}$ & $\mathrm{x}$ & $\mathrm{x}$ \\
\hline Uncertainty & & $15 \%$ & $13 \%^{b}$ & $15 \%^{\mathrm{c}}$ & - & $<15 \%{ }^{\mathrm{d}}$ \\
\hline Technology & Low & - & - & - & - & $\mathrm{x}$ \\
\hline \multirow[t]{2}{*}{ Complexity } & Medium & $\mathrm{x}$ & $\mathrm{x}$ & - & - & - \\
\hline & High & - & - & $\mathrm{x}$ & $\mathrm{x}$ & - \\
\hline $\begin{array}{l}\text { New construction } \\
\text { For 2-point measu }\end{array}$ & $\begin{array}{l}\text { refurbishments } \\
\text { ments }\end{array}$ & & & $\begin{array}{l}\text { balance } \\
\text { her pres }\end{array}$ & ressurizat & hod \\
\hline
\end{tabular}

The standardized method, ISO 9972, is commonly used for quantitative verification of air tightness of new and existing buildings in all three countries. Since it is an international standard, the use of this method promotes comparisons of building air tightness between countries. But the method can be difficult to use in large or tall buildings, very leaky buildings or buildings where it is impossible to seal or close required openings. Big or tall buildings include both new and existing buildings, but very leaky buildings or buildings where the openings are difficult to seal are more often found in existing buildings. Because of this, alternative methods are more often used on existing buildings.

The results from the quantitative air tightness measurements can be presented in different ways. Air change rate, normalized by internal volume, is most commonly used worldwide. A reason for this is that it is also used for ventilation measurements. For buildings with natural ventilation, these also include the air leakage. Air permeability is normalized by the enclosing area. The distinction of enclosing area can be ambiguous for apartments; surfaces only towards the outside or surfaces both towards the outside and towards inner spaces are used in different cases. The specific leakage rate is normalized by the floor area, which 
is calculated slightly differently between the countries. To achieve a comparable measurement of air tightness, both common measurement methods and commonly defined units of measurement are needed.

Measuring air tightness with low pressure differentials over the envelope may result in higher uncertainty due to influence from the wind. Measurements with high pressure differentials on the other hand do not directly measure the infiltration at natural conditions. Measurements should be performed over a range of pressures to make the extrapolation to lower pressure differentials more accurate. There are also ways to determine infiltration at natural pressure, with as little climatic interference as possible (e.g. AC pressurization).

\section{Conclusion}

The methods can be classified based on their aim, application in different stages of the buildings lifecycle, suitability for different kinds of buildings and measured quantity. The standard ISO 9972 is used for verification of air tightness in all three countries, but alternative methods exist that might be more suitable in certain cases. Simple methods can be used to identify leaks in the building process; two or more can be combined to increase accuracy. To achieve a comparable measurement of air tightness, both common measurement methods and commonly defined units of measurement are needed. This review will be used in further work to compose recommendations for different buildings and situations. Some of the recommended methods will also be tested in real situations, to evaluate the recommendations and possibly improve the methods.

\section{Nomenclature}

$\begin{array}{llll}q_{\Delta p} & \text { air permeability } & {\left[\mathrm{m}^{3} / \mathrm{hm}^{2}\right]\left[1 / \mathrm{sm}^{2}\right]} & \text { envelope area } \\ w_{\Delta p} & \text { specific leakage rate } & {\left[\mathrm{m}^{3} / \mathrm{hm}^{2}\right]} & \text { floor area } \\ n_{\Delta p} & \text { air change rate/ACH } & {[1 / \mathrm{h}]} & \text { internal volume } \\ \text { ELA } & \text { effective leakage area } & {\left[\mathrm{m}^{2}\right]} & \text { floor area }\end{array}$

\section{Acknowledgements}

This study is done as a part of the Interreg IVA Nord funded project IEEB Increasing Energy Efficiency in Buildings. The authors would like to thank Clara Good and Norut- Northern Research Institute in Norway as well as Kauko Tulla and Oulu University of Applied Sciences in Finland, for their contributions.

\section{References}

[1] O. Hassan, An integrated management approach to designing sustainable buildings, JEAPM, Volume 8, Issue 2, 2006. 
[2] EU, Directive 2010/31/EU of the European parliament and of the council on the energy performance of buildings, EU, 2010.

[3] M. Sherman, Building Airtightness: Research and Practice, Lawrence Berkley National Laboratory, 2009.

[4] E. Sikander and P. Wahlgren, Alternativa metoder för utvärdering av byggnadsskalets lufttäthet, SP, 2008.

[5] F. Carrie and B. Rosenthal, An overview of national trends in envelope and ductwork airtightness, AIVC, 2008.

[6] H. Fennell and J. Haehnel, Setting Airtightness Standards, ASHRAE, 2005.

[7] M. J. Limb, A Review of International Ventilation, Airtightness, Thermal Insulation and Indoor Air Quality Criteria, AIVC, 2001.

[8] J. McWilliams, Review of Airflow Measurement Techniques, Lawrence Berkley National Laboratory, 2002.

[9] M. Sherman, Air Infiltration Measurement Techniques, Lawrence Berkley Laboratory, 1998.

[10] S. Caillou and D. V. Orshoven, Report on the building airtightness measurement method in European countries, ASIEPI, 2010.

[11] ISO 140 Acoustics - Measurement of sound insulation in buildings and of building elements, ISO, 1998.

[12] O. Hassan, Building Acoustics and Vibration, Theory and Practice, World Scientific, 2009.

[13] EN 13187 (ISO6781:1993 modified) Thermal performance of buildings Qualitative detection of thermal irregularities in building envelopes Infrared method, CEN, 1993.

[14] Standard SFS 5511 Air, Indoor climate, Field measurements of the thermal environment, SFS, 1991.

[15] Health instruction regarding physical, chemical and biological factors in housing and other living premises, The ministry of Social Affairs and Health, 2003.

[16] Paloniitty and T. Kauppinen., Thermography of buildings, Helsinki: Construction industry in Finland, 2006.

[17] RT 14-10850 Thermography of building, thermal insulation, RT, 2005.

[18] ISO 7726 Ergonomics of the thermal environment - Instruments for measuring physical quantities, ISO, 1998.

[19] ISO 7730 Ergonomics of the thermal environment - Analytical determination and interpretation of thermal comfort using calculation of the PMV and PPD indices and local thermal comfort criteria, ISO, 2005.

[20] EN 13182 - Ventilation for buildings - Instrumentation requirements for air velocity measurements in ventilated spaces, European Standard, 2002.

[21] LVI 014-10187 Air-conditioning, Indoor climate, Field measurements of the thermal environment, Rakennustieto, 1991.

[22] RT 07-10946 Indoor air quality guides, RT, 2009.

[23] ASTM E1186 - 03 Standard Practices for Air Leakage Site Detection in Building Envelopes and Air Barrier Systems, ASTM, 2009.

[24] J. Kronvall, Mätningar och mätmetoder för lufttäthet, Stockholm: Statens råd för byggnadsforskning, 1979. 
[25] ASTM E741-11 Standard Test Method for Determining Air Change in a Single Zone by Means of a Tracer Gas Dilution, ASTM, 2011.

[26] ISO 12569 Thermal insulation in buildings - Determination of air change in buildings - Tracer gas dilution method, ISO, 2000.

[27] Buildings: Total outdoor air inflow (NT VVS 055), Nordtest, 1987.

[28] Ventilation: Flow rate, total effective -by single zone approximation (NT VVS 105), Nordtest, 1994.

[29] EN 13829 Thermal performance of buildings - determination of air permeability of buildings - Fan pressurization method (ISO 9972:1996, modified), Brussels: CEN, 2000.

[30] ISO 13790 Energy performance of buildings - Calculation of energy use for space heating and cooling, ISO, 2008.

[31] RT 80-10974 Industrialized manufactured apartment buildings air tightens quality control guide, RT, 2009.

[32] I. Walker, D. Wilson and M. H. Sherman, A comparison of the power law to quadratic formulations for air infiltration calculations, Energy and Buildings, Vol. 27, No.3, 1997.

[33] Standard Test Methods for Determining Airtightness of Buildings Using an Orifice Blower Door, ASTM, 2007.

[34] J. Reardon, A. Kim and C. Shaw, Balanced Fan Depressurization Method for Measuring Component and Overall Air Leakage in Single- and Multifamily Leakage in Single- and Multifamily, ASHRAE Transactions, 1987.

[35] B. Mattsson, Studies on Building air leakage - a transient method, measurements and modeling, Göteborg: Department of Civil and Environmental Engineering, Chalmers, 2007.

[36] CAN/CGSB-149.15-96 Determination of the Overall Envelope Airtightness of Buildings by the Fan Pressurization Method Using the Building's Air Handling System, Ottawa: CGSB, 1996.

[37] J. Jeong, J. Firrantello, W. Bahnfleth, J. Freihaut and A. Musser, Case studies of building envelope leakage measurement using an air-handler fan, BSER\&T, 29(2), 2008.

[38] H. Awbi, Ventilation of buildings, Spon, 2003.

[39] ISO 717 Rating of sound insulation in buildings and of building elements, ISO, 1996. 